\title{
Abundance of Plant-Associated Gammaproteobacteria Correlates with Immunostimulatory Activity of Angelica sinensis
}

\author{
Kriti Kalpana 1,2 (D), Diego Montenegro ${ }^{1,2}$, Giovanna Romero ${ }^{1}$, Ximena Peralta ${ }^{1}$, \\ Betul Akgol Oksuz ${ }^{3}$, Adriana Heguy ${ }^{3}$, Moriya Tsuji ${ }^{4}$ and Akira Kawamura ${ }^{1,2,5, *(D)}$ \\ 1 Department of Chemistry, Hunter College of CUNY, New York, NY 10065, USA; \\ kritikalpana@gmail.com (K.K.); diego.montenegro@gmail.com (D.M.); gioromero25@gmail.com (G.R.); \\ Ximenaperalta613@gmail.com (X.P.) \\ 2 Biochemistry Ph.D. Program, The Graduate Center of CUNY, New York, NY 10016, USA \\ 3 Genome Technology Center, NYU Langone Medical Center, New York, NY 10016, USA; \\ Betul.AkgolOksuz@umassmed.edu (B.A.O.); Adriana.Heguy@nyulangone.org (A.H.) \\ 4 HIV and Malaria Vaccine Program, Aaron Diamond AIDS Research Center, Affiliate of The Rockefeller \\ University, New York, NY 10016, USA; mtsuji@adarc.org \\ 5 Chemistry Ph.D. Program, The Graduate Center of CUNY, New York, NY 10016, USA \\ * Correspondence: akawamur@hunter.cuny.edu; Tel.: +1-212-650-3095
}

Received: 10 April 2019; Accepted: 27 May 2019; Published: 31 May 2019

\begin{abstract}
Background: Angelica sinensis is a medicinal plant known for a variety of biological effects, including its ability to stimulate innate immune cells in humans. Recent studies indicate that the immunostimulatory activity of $A$. sinensis arises from microbe-associated molecular patterns (MAMPs) of plant-associated bacteria. However, it is unknown which bacterial taxa in A. sinensis are responsible for the production of immunostimulatory MAMPs. Methods: Samples of $A$. sinensis were subjected to a cell-based assay to detect monocyte-stimulation and 16S ribosomal RNA amplicon sequencing, which revealed their immunostimulatory activity and microbial communities. The resulting data were analyzed by Linear discriminant analysis effect size (LEfSe), an online biostatistical tool for metagenomic biomarker discovery, to identify the bacterial taxonomical features correlated with the immunostimulatory activity. Results: A series of bacterial taxa under Gammaproteobacteria correlated positively with the immunostimulatory activity, whereas several Gram-positive taxa and Betaproteobacteria correlated negatively with the activity. Conclusions: The identified bacterial taxa set a new stage to characterize immunostimulatory MAMPs in plants.
\end{abstract}

Keywords: microbe-associated molecular pattern (MAMP); lipopolysaccharide (LPS); Angelica sinensis; Dong quai; Shi-Quan-Da-Bu-Tang; Juzen-taiho-to

\section{Introduction}

Plants harbor numerous and diverse microbes. Plant-associated microbes play vital roles in the health of plants by producing nutrients, degrading wastes, and protecting their hosts from pathogens [1]. However, plants may not be the only beneficiaries of these microbes. Humans consume vegetables, fruits, and herbs, with which plant-associated microbes are also ingested. Although ingested microbes might not survive the passage through the stomach acid, their metabolites can remain intact and exhibit biological effects. Recent studies suggest that microbe-associated molecular patterns (MAMPs) of plant-associated bacteria modulate the human immune system. In a study on Echinacea, an immune-boosting medicinal herb, Pasco and co-workers revealed that MAMPs are responsible for the ability of Echinacea to stimulate innate immune cells, such as macrophages [2,3]. 
They also found a correlation between the total bacterial load in Echinacea and macrophage activity [4]. Independently, Cech and co-workers found that Echinacea, when grown under a germ-free condition, did not stimulate innate immune cells [5], which further underscored the importance of MAMPs for the immunostimulatory activity of Echinacea. Recently, our group found that lipopolysaccharides (LPSs), prototypical MAMPs of Gram-negative bacteria, are the key immunostimulants in Juzen-taiho-to (JTT) [6], which is an immune-boosting herbal formulation in East Asia; JTT is clinically used in Japan to boost the immunological functions of patients with cancer [7-9], hepatitis C [10], otitis [11], and anemia [12]. These findings support the emerging notion that MAMPs of environmental bacteria play important roles in the development and maintenance of our immune system $[13,14]$.

Although the MAMPs of human pathogens, also known as pathogen-associated molecular patterns (PAMPs), have long been the subject of biomedical research, little is currently known about the MAMPs of phytobacteria. A few known ones, including the LPSs of Rhizobium etli, elicit little or no immunological responses [15]. As such, it had been generally assumed that phytobacterial MAMPs are structurally too diverged from PAMPs to exhibit immunological effects. The recent findings of immunostimulatory MAMPs in Echinacea and JTT, however, suggest that phytobacterial MAMPs can serve as an untapped source of immunostimulatory agents. Thus, it is important to start characterizing their chemical structures as well as immunological effects.

It is, however, not a trivial task to characterize immunostimulatory MAMPs in plants. Each plant contains numerous and diverse bacteria. Each bacterium produces multiple MAMPs. As such, plants contain enormously complex mixtures of MAMPs from hundreds or possibly thousands of different bacterial species. Furthermore, the amounts of individual MAMPs in plants are minuscule compared to phytochemicals produced by plants. The staggering chemical complexity as well as minuscule quantities defy the classical approach of natural products chemistry; that is, purification of active compounds followed by structural and biological characterization. Even if a few MAMPs could be purified, it would not help in terms of gaining a holistic understanding of the immunostimulatory activity of medicinal plants.

An alternative approach is to harness the enormous screening power of amplicon sequencing. The genetic data of bacteria, such as $16 \mathrm{~S}$ ribosomal RNA (16S rRNA), can be amplified in the presence of plant DNA. Amplified bacterial genes can then be sequenced to obtain comprehensive profiles of bacterial communities in plants, which reflect the diversity of MAMPs. The resulting data can be subjected to bioinformatics analyses to find the taxa correlated with the immunostimulatory activity of plants. Once the bacterial taxa of interest are identified, subsequent studies can focus on their MAMPs to understand their effects on the human immune system. Although various Gram-negative taxa have been detected in immune-boosting plants previously $[6,16]$, it remains to be determined which bacterial taxa are correlated with the immunostimulatory activity.

Here, we present the phytobacterial taxa that correlate with the in vitro immunostimulatory activity of Angelica sinensis, which is a key component herb in JTT [6]. In this study, the immunostimulatory activity of $A$. sinensis was first examined by a cell-based assay using THP-1 monocytes, which revealed a substantial sample-to-sample variation. In addition, the microbial community structure of $A$. sinensis was determined by $16 \mathrm{~S}$ rRNA amplicon sequencing, which also revealed a large sample-to-sample variation. The immunological data and the $16 \mathrm{~S}$ profiles were then subjected to Linear discriminant analysis effect size (LEfSe) [17]. The LEfSe analysis revealed several bacterial taxa strongly correlated with the immunostimulatory activity of $A$. sinensis. The identified taxa provide a new basis to start characterizing immunostimulatory MAMPs in plants.

\section{Materials and Methods}

\subsection{Materials}

The solvents for extraction and purification were HPLC grade and were purchased from VWR (Radnor, PA, USA) and Fisher Scientific (Waltham, MA, USA). Four different batches (dried roots) of 
A. sinensis (Dong quai), namely, AS1, AS2, AS3, and AS4, were obtained from local Chinese Pharmacies in New York, NY, USA. Unless specified otherwise, all other chemicals and reagents were obtained from Fisher Scientific and VWR and used without further purification.

\subsection{Preparation of A. sinensis Extracts for the Cell-Based Assay}

Dried pieces of A. sinensis ( $10 \mathrm{~g})$ were extracted with boiling water $(100 \mathrm{~mL})$ for one hour. Insoluble materials were removed by vacuum filtration. The filtrate was dried and reconstituted in DMSO to obtain a stock solution of $A$. sinensis extract $(1 \mu \mathrm{g} / \mu \mathrm{L})$ for cell treatments.

\subsection{Cell Culture}

THP-1 monocytes were purchased from ATCC and cultured in RPMI-1640 medium containing $25 \mathrm{mM}$ HEPES and L-glutamine (HyClone) and supplemented with 10\% (v/v) fetal bovine serum (Fisher), $0.005 \mathrm{mM} \beta$-mercaptoethanol (Fisher), and a mixture of $1 \%(v / v)$ penicillin, streptomycin, and amphotericin $\mathrm{B}$ (VWR). The cells were maintained at $37^{\circ} \mathrm{C}$ in a $5 \% \mathrm{CO}_{2}$ incubator.

\subsection{Cell Treatment and RNA Purification}

THP-1 cells were plated at a concentration of 500,000 cells/2 mL in each well of a 12-well plate. On the following day, cells were treated with $A$. sinensis extracts to achieve a final concentration of $5 \mu \mathrm{g} / \mathrm{mL}$, positive control (JTT at $100 \mu \mathrm{g} / \mathrm{mL}$ and LPS at $0.1 \mathrm{ng} / \mathrm{mL}$ ), or DMSO as the vehicle control, for $4 \mathrm{~h}$ in a $37^{\circ} \mathrm{C}$ incubator and $5 \% \mathrm{CO}_{2}$. After $4 \mathrm{~h}$, cells were transferred to a $15 \mathrm{~mL}$ Falcon tube and centrifuged at $1300 \times \mathrm{rpm}$ for $5 \mathrm{~min}$ at room temperature. The medium was aspirated, and the pellet was subjected to RNA purification using an E.Z.N.A. Total RNA Kit I (Omega Bio-Tek, Norcross, GA, USA). The resulting RNA samples were quantified by $\mathrm{UV}_{260}$ absorption, which was measured by a NanoDrop 1000 Spectrophotometer (Thermo Fisher, Waltham, MA, USA). Samples showing the $260 \mathrm{~nm} / 280 \mathrm{~nm}$ ratios between 1.8 and 2.2 were used for cDNA synthesis.

\subsection{Reverse Transcription and Quantitative Polymerase Chain Reaction}

The purified RNA samples were used to prepare cDNA by reverse transcription (RT). For each RT reaction, $1 \mu \mathrm{L}$ of a $10 \mathrm{mM}$ dNTP Mix (Promega) and $2 \mu \mathrm{L}$ of random primers $(0.3 \mu \mathrm{g} / \mu \mathrm{L}$, Invitrogen) were added to $13 \mu \mathrm{L}$ of RNA samples $(200 \mathrm{ng} / \mu \mathrm{L})$. The mixture was placed in a PCR thermocycler for $3 \mathrm{~min}$ at $70{ }^{\circ} \mathrm{C}$ and then cooled to $4{ }^{\circ} \mathrm{C}$ for $1 \mathrm{~min}$. To each of the reaction tubes, $4 \mu \mathrm{L}$ of $5 \times \mathrm{RT}$ buffer and $0.5 \mu \mathrm{L}$ of $200 \mathrm{U} / \mu \mathrm{L}$ M-MLV Reverse Transcriptase (Promega) were added. The resulting mixture was incubated at $42{ }^{\circ} \mathrm{C}$ for $1 \mathrm{~h}$ and then heated to $95^{\circ} \mathrm{C}$ for $10 \mathrm{~min}$. Finally, the mixture was incubated at $37^{\circ} \mathrm{C}$ for $20 \mathrm{~min}$. The synthesized cDNA samples were diluted with diethyl pyrocarbonate (DEPC) treated water to $0.025 \mu \mathrm{g} / \mu \mathrm{L}$ for quantitative polymerase chain reaction (qPCR) analysis. The expression level of intercellular adhesion molecule 1 (ICAM-1) in each sample was determined by Taqman ${ }^{\circledR}$ Gene Expression assays (Applied Biosystems) using a 7500 Real-Time PCR system (Applied Biosystems, Beverly, MA, USA), in which GAPDH was used as the endogenous control. For each sample, triplicate experiments were carried out. The relative gene expression or fold-change (relative quantitation) was calculated by the $\Delta \Delta \mathrm{C}_{\mathrm{T}}$ method.

\subsection{DNA Extraction from A. sinensis for $16 S \mathrm{rRNA}$ Amplicon Sequencing}

For each DNA extraction, dried pieces of $A$. sinensis sample (ca. $0.25 \mathrm{~g}$ ) were ground to powder containing 2-5 mm particles using a coffee bean grinder. The resulting powder was subjected to DNA isolation using the MoBio PowerLyzer ${ }^{\circledR}$ PowerSoil ${ }^{\circledR}$ DNA Isolation kit. Purified DNA samples were quantified with Nanodrop ${ }^{\circledR}$ to obtain approximately 1.2-1.6 $\mu \mathrm{g}$ of DNA per sample. DNA extraction was carried out in three independent replicates for each sample of $A$. sinensis. 


\section{7. $16 S$ rRNA Amplicon Sequencing and Data Analysis}

DNA samples, which contained DNA from both microbes and plants, were subjected to $16 \mathrm{~S}$ rRNA amplicon sequencing. The study used the primer pair (799f/1114r) that can selectively amplify bacterial 16S rRNA genes in the presence of chloroplast and mitochondrial DNA from A. sinensis samples. Although another primer pair (799f/1392r) is more commonly used to amplify bacterial $16 \mathrm{~S}$ rRNA from plant samples, our preliminary PCR analysis of $A$. sinensis with the 799f/1392r primer pair gave an unexpectedly large PCR amplicon as well as the expected product. On the other hand, from the 799f/1114r primer pair, which has been used to amplify $16 \mathrm{~S}$ rRNA from Chinese cabbage [18], a single PCR product was obtained. Thus, the current study used the $799 \mathrm{f} / 1114 \mathrm{r}$ primer pair. The study followed the 16S Illumina sequencing protocol as described by Caporaso et al. [19], which gave $2 \times 300$ Illumina MiSeq reads. After quality analysis of the raw reads (Illumina BaseSpace, San Diego, CA, USA) and fastq raw sequence file generation, the data set was subjected to analysis with Quantitative Insights Into Microbial Ecology (QIIME) version 1.8 [20] on Amazon EC2 Cloud Computing Clusters. Barcodes were extracted from the raw reads, and the headers of forward reads were matched with those of corresponding reverse reads. Paired-ends were joined (a minimum overlap of 10 bases; a percent maximum difference of $20 \%$ ). The joined reads were then demultiplexed with a Phred quality score threshold of Q20 or higher. The high quality reads were subjected to a closed-reference operational taxonomic unit (OTU)-picking process using the BLAST algorithm aligning reads against the GREENGENES (gg_otus-13_8-release) 97_otu database, followed by phylogenetic diversity analysis with a sampling depth of 5000 sequences per sample.

The potential metagenomic biomarkers were identified by LEfSe [17] on the Galaxy platform [21]. The OTU table (Supplementary Table S1) from the QIIME analysis was subjected to LEfSe. LEfSe detected OTU-features with significant differences between the High and Low activity groups by class and sub-class comparison analyses using the Kruskal-Wallis sum-rank test (Alpha value threshold: 0.05) and the Wilcoxon rank-sum test (Alpha value threshold: 0.05), respectively. Finally, the effect size of each differentially abundant feature was estimated by Linear Discriminant Analysis (LDA) to obtain microbial taxa with LDA values of 4.5 or higher, which is much more stringent than the default threshold of LEfSe (LDA = 2).

\section{Results}

Four different samples of $A$. sinensis (AS1, AS2, AS3, and AS4) were examined in the current study. The immunostimulatory activity was determined by the messenger RNA (mRNA) induction of ICAM-1 in human THP-1 monocytes [22]. In this assay, induction of ICAM-1 mRNA in THP-1 cells was determined based on the comparison with the DMSO control. This assay indicated that the four samples (AS1, AS2, AS3, AS4) could be grouped into two classes, namely, (1) Low activity (AS1, AS2) and (2) High activity (AS3, AS4) (Figure 1). While the low-activity samples (AS1, AS2) caused about 10-fold induction of ICAM-1 in THP-1 monocytes, the high-activity samples (AS3, AS4) exhibited around 100-fold induction. The two classes (Low and High) of A. sinensis samples set the stage to look for differentially abundant bacterial taxa.

16S rRNA amplicon sequencing was carried out with Illumina MiSeq using a primer pair (799f/1114r) that minimizes the co-amplification of chloroplast and mitochondrial DNA in plants [23]. For each $A$. sinensis sample, three independent replicates were made to account for the possible variability within the same sample. As such, a total of 12 DNA samples were prepared and subjected to the amplicon sequencing. The sequencing revealed diverse bacterial communities with a total of 859 different genera (Figure 2). The sequencing also showed that each sample harbors a distinctly different bacterial community. Even the replicates of the same sample showed some variability, suggesting that each sample consists of a heterogeneous mixture of the dried pieces of $A$. sinensis. It appeared that several genera in the class of Gammaproteobacteria were associated with the High-activity group, such as Pseudomonas and Rahnella, although more rigorous statistical analysis was needed to examine the correlation. 


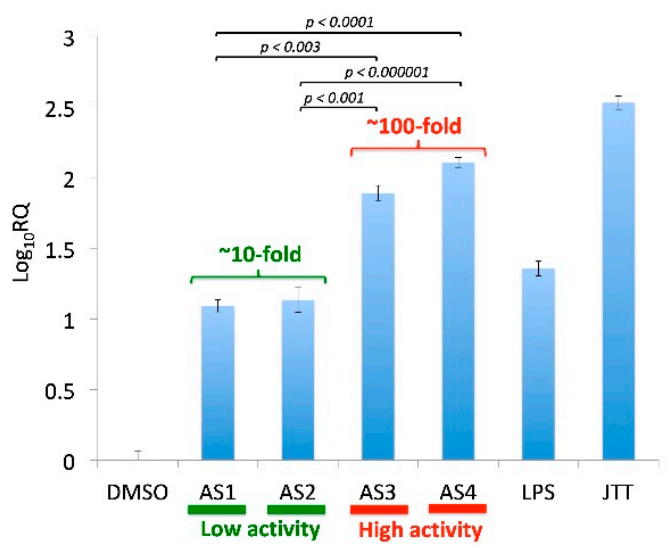

Figure 1. Immunostimulatory activity of four Angelica sinensis samples. The activity was measured by qRT-PCR of ICAM-1 in THP-1 monocytes. Cells were treated with samples for four hours; JTT (Juzen-taiho-to, $100 \mu \mathrm{g} / \mathrm{mL}$, positive control); lipopolysaccharide (LPS) (Escherichia coli LPS, $0.1 \mathrm{ng} / \mathrm{mL}$, positive control), A. sinensis samples (5 $\mu \mathrm{g} / \mathrm{mL})$; DMSO (vehicle control). Each sample was analyzed at least in triplicate $(n=3)$. RQ (Relative Quantitation): fold change. AS3 and AS4 showed much higher activities (77-fold and 128-fold, respectively) than AS1 and AS2 (both 12-fold).

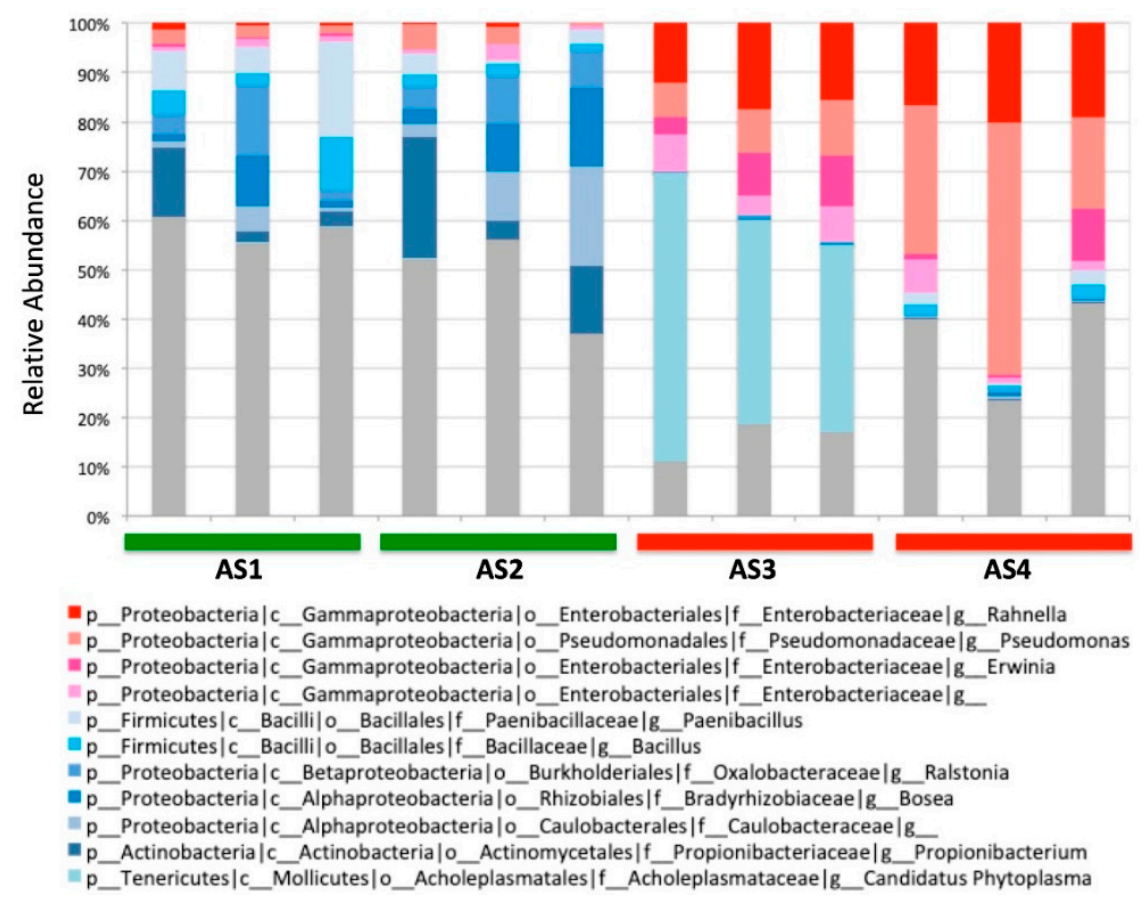

Figure 2. Microbial communities of four A. sinensis samples at the genus level. The most abundant genera are shown. The genera in the class Gammaproteobacteria are colored in reddish hues. Other abundant genera are shown in bluish colors. Three independent replicates were made for each sample. p: phylum; c: class; o: order; f: family; g: genus.

In order to identify the taxonomic features correlated with the two classes of immunostimulatory activity (Low and High), the bacterial profiles were analyzed by LEfSe [17], which examines not only the statistical significance of differentially distributed features but also evaluates biological consistency and effect size. We used LEfSe for the current study because, in addition to its statistical rigor, LEfSe is an online tool on the Galaxy platform [24], which is available to any researcher interested in similar metagenomic biomarker analyses of medicinal plants.

LEfSe identified 19 differentially abundant clades with a linear discriminant analysis (LDA) score of 4.5 or above (Figure 3). Seven clades were abundant in the High activity group: namely, one class 
(Gammaproteobacteria), two orders (Enterobacteriales and Pseudomonadales), two families (Enterobacteriaceae and Pseudomonadaceae), and two genera (Rahnella and Pseudomonas). On the other hand, the abundant clades in the Low-activity group were two phyla (Firmicutes and Actinobacteria), three classes (Bacilli, Actinobacteria, and Betaproteobacteria), two orders (Actinomycetales and Burkholderiales), three families (Propionibacteriaceae, Paenibacillaceae, and Oxalobacteraceae) and two genera (Propionibacterium and an undefined genus in the Caulobacteraceae family).

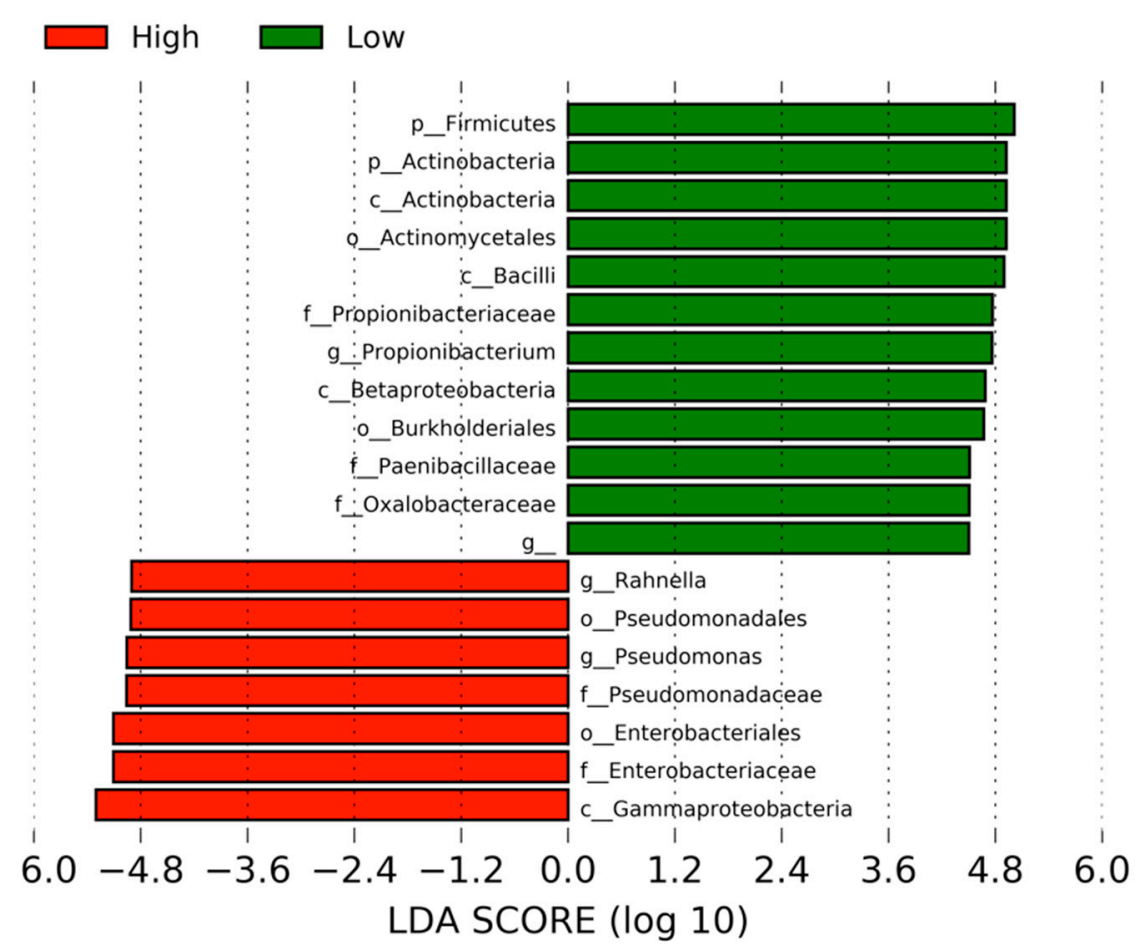

Figure 3. Differentially abundant clades between the high- and low-activity samples of $A$. sinensis. The clades correlated with the High monocyte activity are shown in red, whereas those correlated with the Low activity are in green. The default linear discriminant analysis (LDA) threshold in Linear discriminant analysis effect size (LEfSe) is 2.0. The higher threshold makes the analyses more stringent.

When the discriminative clades were visualized by the cladogram, the High- and Low-activity groups were clearly separated (Figure 4). The clades correlated with the High-activity group were all localized within Gammaproteobacteria, which is a class of Gram-negative bacteria. On the other hand, the Low-activity clades were seen in two phyla of Gram-positive bacteria (Firmicutes and Actinobacteria) and a class of Gram-negative bacteria (Betaproteobacteria).

Closer examination of the observed clades at the genus level revealed that some genera were more consistently associated with the activity than others (Figure 5). For example, the genus Rahnella was consistently higher in the High-activity samples than in the Low-activity group (Figure 5a). On the other hand, the abundance of the genus Pseudomonas varied within the High-activity samples, although it was still significantly higher in the High-activity samples (Figure 5b). Likewise, the abundance of the Gram-positive genus Ralstonia was consistently higher in the Low-activity samples (Figure 5c), whereas the abundance of the Gram-positive genus Bacillus varied substantially from sample to sample (Figure 5d). 


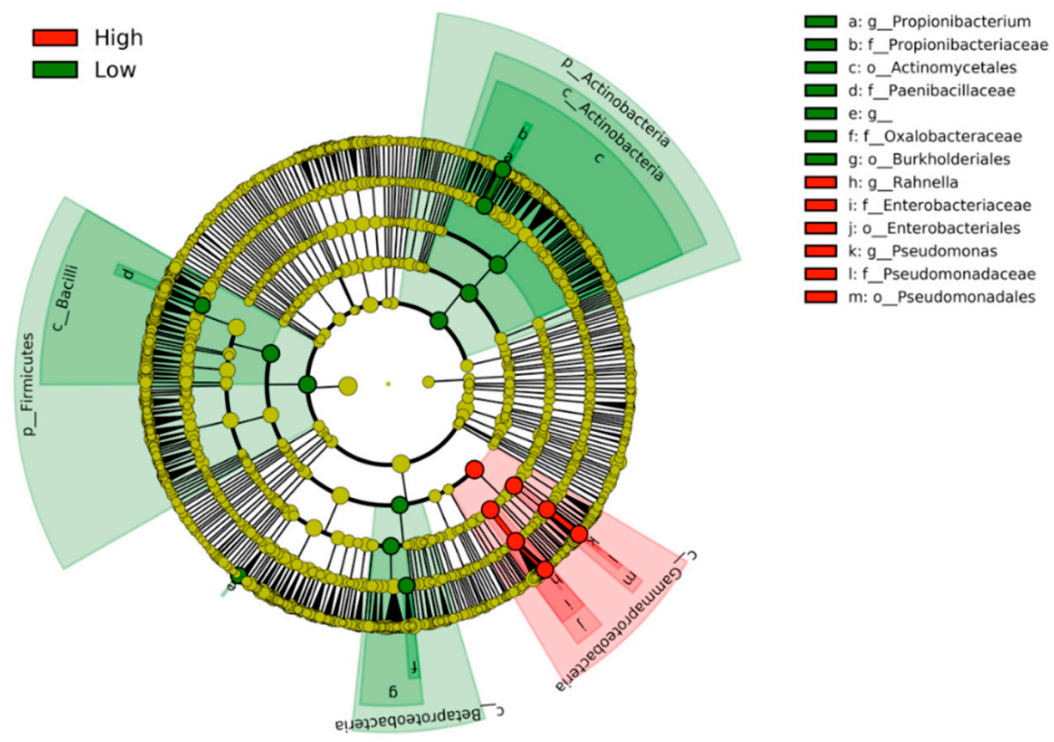

Figure 4. Cladogram showing the distribution of the clades correlated with the High monocyte activity (red) and the Low activity (green). The High-activity clades are clustered within the class Gammaproteobacteria.

(a) Rahnella

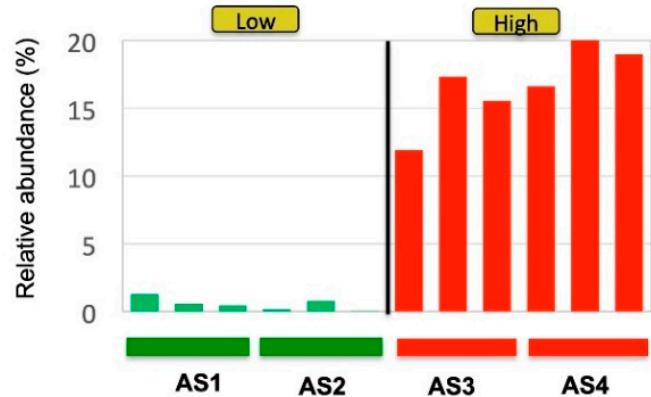

(c) Ralstonia

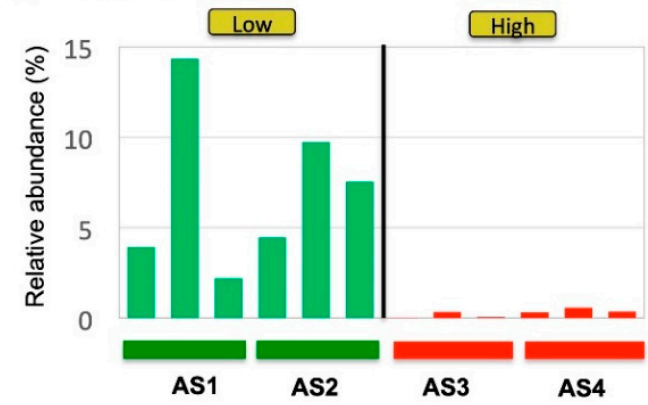

(b) Pseudomonas

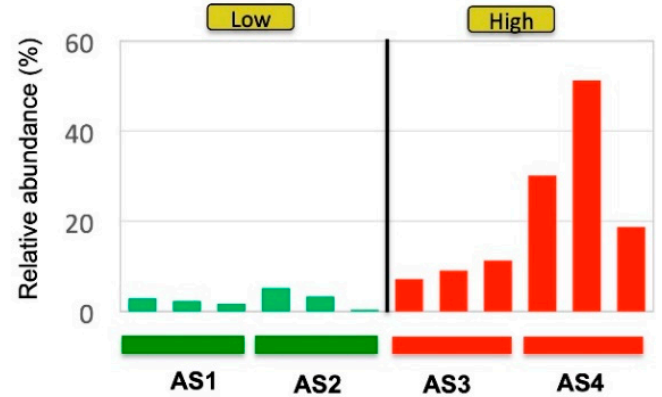

(d) Bacillus

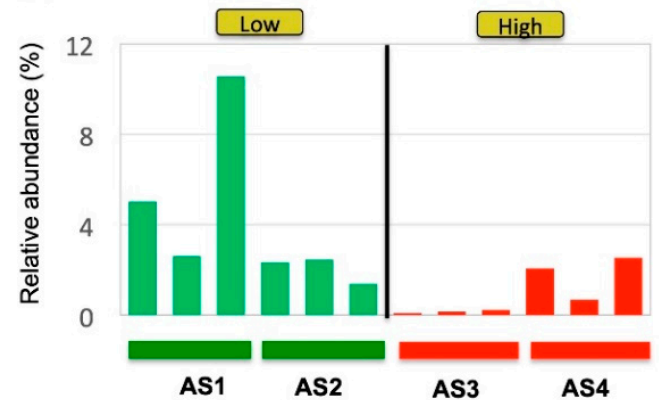

Figure 5. Plots of bacterial genera correlated with the in vitro immunostimulatory activity, (a) Rahnella and (b) Pseudomonas, and Low activity, (c) Ralstonia and (d) Bacillus. Three independent replicates were made for each sample to show the variability of microbial community within the same sample. The genera Rahnella and Pseudomonas were abundant in High-activity samples (AS3 and AS4), whereas Ralstonia and Bacillus were abundant in Low-activity samples (AS1 and AS2).

\section{Discussion}

The advent of powerful sequencing tools has transformed the way we characterize plant-associated microbes. Microbial communities of both phyllosphere and rhizosphere have been characterized for various plants, including Arabidopsis [25,26], maize [27], basil [28], ginger [29], lettuce [30], and Korean ginseng [31]. These studies provided important new insights into plant-microbe interactions, which 
can be translated to agricultural applications, such as development of biocontrol agents and pathogen detection. However, few studies have examined the potential link between plant-associated microbes and therapeutic effects of medicinal plants. To our knowledge, the current study is the first to examine the correlation between the plant-associated microbes and the immunomodulatory activity of $A$. sinensis, which is a key herbal component in JTT [6]. Admittedly, the sample size of the current study is small, which underscores the importance of further studies to verify our findings. Yet, several exciting new hypotheses emerged from the current study as outlined below.

First, the current study revealed the correlation between the abundance of Gammaproteobacteria in A. sinensis and high monocyte activity. The finding suggests that MAMPs of some plant-associated Gammaproteobacteria might elicit strong immunological responses. The class Gammaproteobacteria includes many human pathogens, such as Salmonella, Yersinia, and Vibrio [32]. Although plant-associated Gammaproteobacteria have diverged from human pathogens, their MAMPs might still retain some structural features of PAMPs. Among the bacteria in Gammaproteobacteria, several genera correlated strongly with the high monocyte activity: namely, Rahnella and Pseudomonas. Identification of these genera sets the stage to further characterize their MAMPs, such as LPSs, to see if they are responsible for the immunostimulatory activity of $A$. sinensis. Although there have been studies on the polysaccharide moieties of Rahnella LPSs [33-37], their lipid A moieties, which are responsible for the activation of monocytes, have not been characterized.

Second, the current study also opens a possibility to use the observed taxa as biomarkers to predict the immunostimulatory activity of $A$. sinensis and possibly other medicinal plants. The taxa of interest, such as Gammaproteobacteria, can be quickly quantified by qPCR. As such, it may become possible to standardize the immunostimulatory activity of $A$. sinensis samples by simple qPCR assays. Simple assays to standardize medicinal plants are important because they could mitigate sample-to-sample variability, which has long been a major issue in herbal medicine [38,39]. Although chemical markers have been developed for the quality control of some medicinal plants $[40,41]$, many herbs, including A. sinensis [42], lack effective methods to standardize their quality. Thus, the current study opens an intriguing possibility to use plant-associated bacteria as "biosensors" to control the quality and reproducibility of medicinal plants.

Finally, our study provides a new mechanistic insight into the immunostimulatory effects of JTT and $A$. sinensis (Dong quai). Both JTT and $A$. sinensis are known to stimulate innate immune cells [22,43]. In particular, it is well-recognized that JTT exhibits "LPS-like" immunological effects [44,45] as evidenced by very similar gene expression profiles of JTT and LPS [22,46]. The current study further corroborates the emerging notion that humans may be benefiting from plant-associated bacteria through the practice of herbal medicine.

In conclusion, the current study revealed a correlation between plant-associated Gammaproteobacteria and in vitro immunostimulatory activity of $A$. sinensis. The finding sets the stage for further studies to characterize the potential roles of plant-associated bacteria in $A$. sinensis and other immunostimulatory medicinal plants.

Supplementary Materials: The following are available online at http://www.mdpi.com/2305-6320/6/2/62/s1, Table S1: OTU Table (Level 6: the genus level) from the QIIME 1.8.0 analysis.

Author Contributions: Study concept and design: K.K., D.M., and A.K.; RT-qPCR, K.K.; 16S rRNA sequencing, K.K., D.M., G.R., X.P., B.A.O., and A.H.; QIIME and LEfSe Analyses, B.A.O. and A.K.; Data interpretation, K.K., M.T., and A.K.; writing - original draft preparation, K.K.; Critical revision of the manuscript: all authors.

Funding: This research was funded by PSC CUNY Grants (TRADB-45-509 and TRADA-46-755) as well as by NIH/NIGMS 1SC3GM094070-01. The NYU Genome Technology Center is supported in part by the Cancer Center Support Grant P30CA016087 at the Laura and Isaac Perlmutter Cancer Center.

Conflicts of Interest: The authors declare no conflicts of interest. 


\section{References}

1. Berg, G.; Koberl, M.; Rybakova, D.; Muller, H.; Grosch, R.; Smalla, K. Plant microbial diversity is suggested as the key to future biocontrol and health trends. FEMS Microbiol. Ecol. 2017, 93. [CrossRef] [PubMed]

2. Pugh, N.D.; Tamta, H.; Balachandran, P.; Wu, X.; Howell, J.; Dayan, F.E.; Pasco, D.S. The majority of in vitro macrophage activation exhibited by extracts of some immune enhancing botanicals is due to bacterial lipoproteins and lipopolysaccharides. Int. Immunopharmacol. 2008, 8, 1023-1032. [CrossRef] [PubMed]

3. Tamta, H.; Pugh, N.D.; Balachandran, P.; Moraes, R.; Sumiyanto, J.; Pasco, D.S. Variability in in vitro macrophage activation by commercially diverse bulk echinacea plant material is predominantly due to bacterial lipoproteins and lipopolysaccharides. J. Agric. Food Chem. 2008, 56, 10552-10556. [CrossRef]

4. Pugh, N.D.; Jackson, C.R.; Pasco, D.S. Total bacterial load within Echinacea purpurea, determined using a new PCR-based quantification method, is correlated with LPS levels and in vitro macrophage activity. Planta Med. 2013, 79, 9-14. [CrossRef]

5. Todd, D.A.; Gulledge, T.V.; Britton, E.R.; Oberhofer, M.; Leyte-Lugo, M.; Moody, A.N.; Shymanovich, T.; Grubbs, L.F.; Juzumaite, M.; Graf, T.N.; et al. Ethanolic Echinacea purpurea Extracts Contain a Mixture of Cytokine-Suppressive and Cytokine-Inducing Compounds, Including Some That Originate from Endophytic Bacteria. PLoS ONE 2015, 10, e0124276. [CrossRef] [PubMed]

6. Montenegro, D.; Kalpana, K.; Chrissian, C.; Sharma, A.; Takaoka, A.; Iacovidou, M.; Soll, C.E.; Aminova, O.; Heguy, A.; Cohen, L.; et al. Uncovering potential 'herbal probiotics' in Juzen-taiho-to through the study of associated bacterial populations. Bioorg. Med. Chem. Lett. 2015, 25, 466-469. [CrossRef]

7. Huang, S.M.; Chien, L.Y.; Tai, C.J.; Chiou, J.F.; Chen, C.S. Effectiveness of 3-week intervention of Shi Quan $\mathrm{Da} \mathrm{Bu}$ Tang for alleviating hematotoxicity among patients with breast carcinoma receiving chemotherapy. Integr. Cancer Ther. 2013, 12, 136-144. [CrossRef] [PubMed]

8. Ogawa, K.; Omatsu, T.; Matsumoto, C.; Tsuchiya, N.; Yamamoto, M.; Naito, Y.; Yoshikawa, T. Protective effect of the Japanese traditional medicine juzentaihoto on myelosuppression induced by the anticancer drug TS-1 and identification of a potential biomarker of this effect. BMC Complement. Altern. Med. 2012, 12, 118. [CrossRef] [PubMed]

9. Zee-Cheng, R.K. Shi-quan-da-bu-tang (ten significant tonic decoction), SQT. A potent Chinese biological response modifier in cancer immunotherapy, potentiation and detoxification of anticancer drugs. Methods Find. Exp. Clin. Pharmacol. 1992, 14, 725-736.

10. Sho, Y.; Fujisaki, K.; Sakashita, H.; Yamaguchi, K.; Tahara, K.; Kubozono, O.; Ido, A.; Tsubouchi, H. Orally administered Kampo medicine, Juzen-taiho-to, ameliorates anemia during interferon plus ribavirin therapy in patients with chronic hepatitis C. J. Gastroenterol. 2004, 39, 1202-1204. [CrossRef] [PubMed]

11. Maruyama, Y.; Hoshida, S.; Furukawa, M.; Ito, M. Effects of Japanese herbal medicine, Juzen-taiho-to, in otitis-prone children-A preliminary study. Acta Otolaryngol. 2009, 129, 14-18. [CrossRef] [PubMed]

12. Nakamoto, H.; Mimura, T.; Honda, N. Orally administrated Juzen-taiho-to/TJ-48 ameliorates erythropoietin (rHuEPO)-resistant anemia in patients on hemodialysis. Hemodial. Int. 2008, 12 (Suppl. 2), S9-S14. [CrossRef] [PubMed]

13. Vatanen, T.; Kostic, A.D.; d’Hennezel, E.; Siljander, H.; Franzosa, E.A.; Yassour, M.; Kolde, R.; Vlamakis, H.; Arthur, T.D.; Hamalainen, A.M.; et al. Variation in Microbiome LPS Immunogenicity Contributes to Autoimmunity in Humans. Cell 2016, 165, 842-853. [CrossRef]

14. Berg, G.; Erlacher, A.; Grube, M. The edible plant microbiome: Importance and health issues. In Principles of Plant-Microbe Interactions; Lugtenberg, B., Ed.; Springer: Cham, Switzerland, 2015; pp. 419-426.

15. Komaniecka, I.; Zdzisinska, B.; Kandefer-Szerszen, M.; Choma, A. Low endotoxic activity of lipopolysaccharides isolated from Bradyrhizobium, Mesorhizobium, and Azospirillum strains. Microbiol. Immunol. 2010, 54, 717-725. [CrossRef] [PubMed]

16. Haron, M.H.; Tyler, H.L.; Pugh, N.D.; Moraes, R.M.; Maddox, V.L.; Jackson, C.R.; Pasco, D.S. Activities and Prevalence of Proteobacteria Members Colonizing Echinacea purpurea Fully Account for Macrophage Activation Exhibited by Extracts of This Botanical. Planta Med. 2016, 82, 1258-1265. [CrossRef]

17. Segata, N.; Izard, J.; Waldron, L.; Gevers, D.; Miropolsky, L.; Garrett, W.S.; Huttenhower, C. Metagenomic biomarker discovery and explanation. Genome Biol. 2011, 12, R60. [CrossRef] [PubMed]

18. Kim, D.; Hong, S.; Kim, Y.T.; Ryu, S.; Kim, H.B.; Lee, J.H. Metagenomic Approach to Identifying Foodborne Pathogens on Chinese Cabbage. J. Microbiol. Biotechnol. 2018, 28, 227-235. [CrossRef] 
19. Caporaso, J.G.; Lauber, C.L.; Walters, W.A.; Berg-Lyons, D.; Huntley, J.; Fierer, N.; Owens, S.M.; Betley, J.; Fraser, L.; Bauer, M.; et al. Ultra-high-throughput microbial community analysis on the Illumina HiSeq and MiSeq platforms. ISME J. 2012, 6, 1621-1624. [CrossRef]

20. Navas-Molina, J.A.; Peralta-Sanchez, J.M.; Gonzalez, A.; McMurdie, P.J.; Vazquez-Baeza, Y.; Xu, Z.; Ursell, L.K.; Lauber, C.; Zhou, H.; Song, S.J.; et al. Advancing our understanding of the human microbiome using QIIME. Methods Enzymol. 2013, 531, 371-444. [CrossRef]

21. Afgan, E.; Baker, D.; Batut, B.; van den Beek, M.; Bouvier, D.; Cech, M.; Chilton, J.; Clements, D.; Coraor, N.; Gruning, B.A.; et al. The Galaxy platform for accessible, reproducible and collaborative biomedical analyses: 2018 update. Nucleic Acids Res. 2018, 46, W537-W544. [CrossRef]

22. Takaoka, A.; Iacovidou, M.; Hasson, T.H.; Montenegro, D.; Li, X.; Tsuji, M.; Kawamura, A. Biomarker-guided screening of Juzen-taiho-to, an oriental herbal formulation for immunostimulation. Planta Med. 2014, 80, 283-289. [CrossRef]

23. Hanshew, A.S.; Mason, C.J.; Raffa, K.F.; Currie, C.R. Minimization of chloroplast contamination in $16 \mathrm{~S}$ rRNA gene pyrosequencing of insect herbivore bacterial communities. J. Microbiol. Methods 2013, 95, 149-155. [CrossRef] [PubMed]

24. LEfSe on the Huttenhower Galaxy Server. Available online: http://huttenhower.sph.harvard.edu/galaxy/ (accessed on 22 May 2019).

25. Bulgarelli, D.; Rott, M.; Schlaeppi, K.; Ver Loren van Themaat, E.; Ahmadinejad, N.; Assenza, F.; Rauf, P.; Huettel, B.; Reinhardt, R.; Schmelzer, E.; et al. Revealing structure and assembly cues for Arabidopsis root-inhabiting bacterial microbiota. Nature 2012, 488, 91-95. [CrossRef]

26. Lundberg, D.S.; Lebeis, S.L.; Paredes, S.H.; Yourstone, S.; Gehring, J.; Malfatti, S.; Tremblay, J.; Engelbrektson, A.; Kunin, V.; del Rio, T.G.; et al. Defining the core Arabidopsis thaliana root microbiome. Nature 2012, 488, 86-90. [CrossRef] [PubMed]

27. Yang, Y.; Wang, N.; Guo, X.; Zhang, Y.; Ye, B. Comparative analysis of bacterial community structure in the rhizosphere of maize by high-throughput pyrosequencing. PLoS ONE 2017, 12, e0178425. [CrossRef] [PubMed]

28. Ceuppens, S.; Delbeke, S.; De Coninck, D.; Boussemaere, J.; Boon, N.; Uyttendaele, M. Characterization of the Bacterial Community Naturally Present on Commercially Grown Basil Leaves: Evaluation of Sample Preparation Prior to Culture-Independent Techniques. Int. J. Environ. Res. Public Health 2015, 12, 10171-10197. [CrossRef] [PubMed]

29. Liu, Y.; Wu, L.; Wu, X.; Li, H.; Liao, Q.; Zhang, X.; Sun, Z.; Li, W. Analysis of Microbial Diversity in Soil under Ginger Cultivation. Scientifica 2017, 2017, 8256865. [CrossRef] [PubMed]

30. Erlacher, A.; Cardinale, M.; Grube, M.; Berg, G. Biotic stress shifted structure and abundance of Enterobacteriaceae in the lettuce microbiome. PLOS ONE 2015, 10, e0118068. [CrossRef]

31. Dong, L.; Cheng, R.; Xiao, L.; Wei, F.; Wei, G.; Xu, J.; Wang, Y.; Guo, X.; Chen, Z.; Chen, S. Diversity and composition of bacterial endophytes among plant parts of Panax notoginseng. Chin. Med. 2018, 13, 41. [CrossRef]

32. Williams, K.P.; Gillespie, J.J.; Sobral, B.W.; Nordberg, E.K.; Snyder, E.E.; Shallom, J.M.; Dickerman, A.W. Phylogeny of gammaproteobacteria. J. Bacteriol. 2010, 192, 2305-2314. [CrossRef]

33. Varbanets, L.D.; Zdorovenko, E.L.; Ostapchuk, A.N. Chemical characteristics and endotoxic activity of the lipopolysaccharide of Rahnella aquatilis 2-95. Microbiology 2008, 77, 298-304. [CrossRef]

34. Zdorovenko, E.L.; Varbanets, L.D.; Zatonsky, G.V.; Kachala, V.V.; Zdorovenko, G.M.; Shashkov, A.S.; Knirel, Y.A. Structure of the O-specific polysaccharide of the lipopolysaccharide of Rahnella aquatilis 95 U003. Carbohydr. Res. 2008, 343, 2494-2497. [CrossRef] [PubMed]

35. Zdorovenko, E.L.; Varbanets, L.D.; Zatonsky, G.V.; Ostapchuk, A.N. Structure of the O-polysaccharide of the lipopolysaccharide of Rahnella aquatilis 1-95. Carbohydr. Res. 2004, 339, 1809-1812. [CrossRef] [PubMed]

36. Zdorovenko, E.L.; Varbanets, L.D.; Zatonsky, G.V.; Ostapchuk, A.N. Structures of two putative O-specific polysaccharides from the Rahnella aquatilis 3-95 lipopolysaccharide. Carbohydr. Res. 2006, 341, 164-168. [CrossRef] [PubMed]

37. Zdorovenko, E.L.; Varbanets, L.D.; Zatonsky, G.V.; Zdorovenko, G.M.; Shashkov, A.S.; Knirel, Y.A. Isolation and structure elucidation of two different polysaccharides from the lipopolysaccharide of Rahnella aquatilis 33071T. Carbohydr. Res. 2009, 344, 1259-1262. [CrossRef] 
38. Heinrich, M. Quality and safety of herbal medical products: Regulation and the need for quality assurance along the value chains. Br. J. Clin. Pharmacol. 2015, 80, 62-66. [CrossRef]

39. Zhou, X.; Li, C.G.; Chang, D.; Bensoussan, A. Current Status and Major Challenges to the Safety and Efficacy Presented by Chinese Herbal Medicine. Medicines 2019, 6, 14. [CrossRef] [PubMed]

40. Bensoussan, A.; Lee, S.; Murray, C.; Bourchier, S.; van der Kooy, F.; Pearson, J.L.; Liu, J.; Chang, D.; Khoo, C.S. Choosing chemical markers for quality assurance of complex herbal medicines: Development and application of the herb MaRS criteria. Clin. Pharmacol. Ther. 2015, 97, 628-640. [CrossRef]

41. Song, X.Y.; Li, Y.D.; Shi, Y.P.; Jin, L.; Chen, J. Quality control of traditional Chinese medicines: A review. Chin. J. Nat. Med. 2013, 11, 596-607. [CrossRef]

42. Giacomelli, N.; Yongping, Y.; Huber, F.K.; Ankli, A.; Weckerle, C.S. Angelica sinensis (Oliv.) Diels: Influence of Value Chain on Quality Criteria and Marker Compounds Ferulic Acid and Z-Ligustilide. Medicines 2017, 4, 14. [CrossRef]

43. Chen, Y.; Duan, J.A.; Qian, D.; Guo, J.; Song, B.; Yang, M. Assessment and comparison of immunoregulatory activity of four hydrosoluble fractions of Angelica sinensisin vitro on the peritoneal macrophages in ICR mice. Int. Immunopharmacol. 2010, 10, 422-430. [CrossRef] [PubMed]

44. Liu, H.; Wang, J.; Tabira, T. Juzen-Taiho-to, an herbal medicine, promotes the differentiation of transplanted bone marrow cells into microglia in the mouse brain injected with fibrillar amyloid beta. Tohoku J. Exp. Med. 2014, 233, 113-122. [CrossRef] [PubMed]

45. Hara, H.; Kataoka, S.; Anan, M.; Ueda, A.; Mutoh, T.; Tabira, T. The therapeutic effects of the herbal medicine, Juzen-taiho-to, on amyloid-beta burden in a mouse model of Alzheimer's disease. J. Alzheimers Dis. 2010, 20, 427-439. [CrossRef]

46. Sharif, O.; Bolshakov, V.N.; Raines, S.; Newham, P.; Perkins, N.D. Transcriptional profiling of the LPS induced NF-kappaB response in macrophages. BMC Immunol. 2007, 8, 1. [CrossRef] [PubMed]

(C) 2019 by the authors. Licensee MDPI, Basel, Switzerland. This article is an open access article distributed under the terms and conditions of the Creative Commons Attribution (CC BY) license (http://creativecommons.org/licenses/by/4.0/). 